\title{
A Case Study on Physicochemical Characteristics of Groundwaters in Greenhouse Areas of Antalya, Turkey
}

\author{
Bülent Topcuoğlu
}

\begin{abstract}
To assess the nitrate and heavy metal pollution, and to understand the ecological and health risks of residents in intensive greenhouse regions of Antalya; a survey study was conducted in groundwaters of intensive greenhouse areas of Antalya, one of the major greenhouse production region of Turkey. Additional to routine water analysis, in groundwaters, several environmental pollution indexes were used to evaluate the size of pollution and risks.

Land altitude of greenhouse regions are varied in a wide range and groundwater table is changed depending on the regions. Physico-chemical characteristics of groundwaters in the majority of greenhouse areas were within the acceptable limit values and differences in characteristics among the regions were found statistically important. Groundwaters have low electrical conductivity, slightly alkaline reaction, low and moderate alkalinity. Dissolved oxygen (DO), biological oxygen demand (BOD), chemical oxygen demand (COD) and total dissolved solids (TDS) were detected in acceptable ranges. Total $\mathrm{NO}_{3}{ }^{-}$values of groundwaters were generally excessed permissible safe limits for drinking waters. Nitrate pollution evaluation values of groundwaters are indicated that due to higher $\mathrm{NO}_{3}{ }^{-}$contents of groundwaters there are a possible health risks for the consumptions of groundwaters as drinking water in a moderate and long-term in the greenhouse regions. High nitrate contents of groundwaters due to agricultural activities all season seem the main threats for public health. Total As and Fe contents of almost all ground waters were above the permissible pollution limits. All other heavy metal concentrations of groundwaters were below the limits. According to evaluation parameters, generally, it can be concluded that all ground waters in regional size may be considered less contaminated, and in point of heavy metals and pollutants is in acceptable limits.
\end{abstract}

Index Terms-Groundwaters, Greenhouse area, Heavy Metals, Nitrate

\section{INTRODUCTION}

Nitrate pollution in intensive greenhouse areas is an important environmental problem that threats sustainable production and national economy and interests particularly for public health. Nitrate poses health risk to humans. It can cause 'blue baby syndrome' or methaemoglobinemia among infant. Nitrate also can cause gastrointestinal illness, multiple digestive tract impairment, indigestion and imflammation of the stomach, gastroenteritis, abdominal pain, dierrhea and blood in the urine and faeces. In addition, low level exposure

Bülent Topcuoğlu is with the Akdeniz University, Vocational School of Technical Sciences, Antalya TURKEY. to nitrate over many years, possibly could cause certain types of cancer such as digestive system cancer, stomach, esophagus, lungs, colon, bladder, ovaries, testicles, urogenital tract and non-hodgkins lymphoma [1].

Aquatic ecosystem is the ultimate recipient of almost everything including heavy metals. Heavy metals in groundwater are toxic even at low concentrations. Pollution of heavy metals in aquatic environment is a growing problem worldwide and currently it has reached an alarming rate. Due to intensive use of agrochemicals in greenhouse soils, nitrate nitrogen and heavy metals is become to common pollutant in ground waters of greenhouse soils and adjacent environment. Especially, high concentration of nitrate nitrogen in groundwaters is accepted as an important indicator of agricultural pollution.

Repeated amendments of organic matter and intensive use of fertilizers, and other agrochemicals may cause soil, ground water and environmental pollution in greenhouses. Although greenhouse areas a have great impact on environment due to intensive use of agrochemicals, little attention has been paid to nitrate and metal accumulation of groundwaters around greenhouses and environmental pollution assessment in ground waters with respect to comprehensive and integrated environmental evaluation.

The impact of agricultural activity on water sources has been widely acknowledged and its impact on surface water of nitrogen) and anthropogenic sources (i.e., industrial residue, intensive agriculture and septic tanks). Among them, heavy used of nitrogenous fertilizers in agricultural activities were the largest contribution of systems has been described in numerous studies [2]. Especially, the relationship between agricultural practices and the dissolution of nitrate in groundwater, as well as other pollutants have been studied in a number of case studies [3]. Nitrate in ground water accumulating from both natural (i.e., soil mineralization and atmospheric deposition nitrate in ground water [4].

Mediterranean region has an important agricultural potential especially greenhouse cultivation with its special climate and geographical characteristics in Turkey. Greenhouse cultivation has resulted in increasing usage of nitrogenous fertilizers and in recent years, many research findings have indicated that an extreme fertilizer and pesticide applications in the greenhouse soils of Mediterranean region. Crop plants which are cultivated in contaminated soils can accumulate contaminants and transfer them to animals and human beings via food chain which are eventually result in 
various health problems. Additionally, nitrate was more affects the ground water rather than phosphates in which related to agricultural activities and animal farming [5].

Assessment of extent of pollution in ground waters come into prominence with regard to prevention of possible risks. The aim of this study was to provide information on the nitrate levels in ground water and measure the groundwater pollution.

\section{MAterial AND MethodS}

Geography of study region: The experiment was conducted on the major greenhouse vegetable growing area located at Antalya, Turkey. The site studied is intensively cultivated and is not industrialized area. The experiment was carried out at greenhouse region and water samples were taken from 10 subregion and 162 sampling points (Fig. 1).

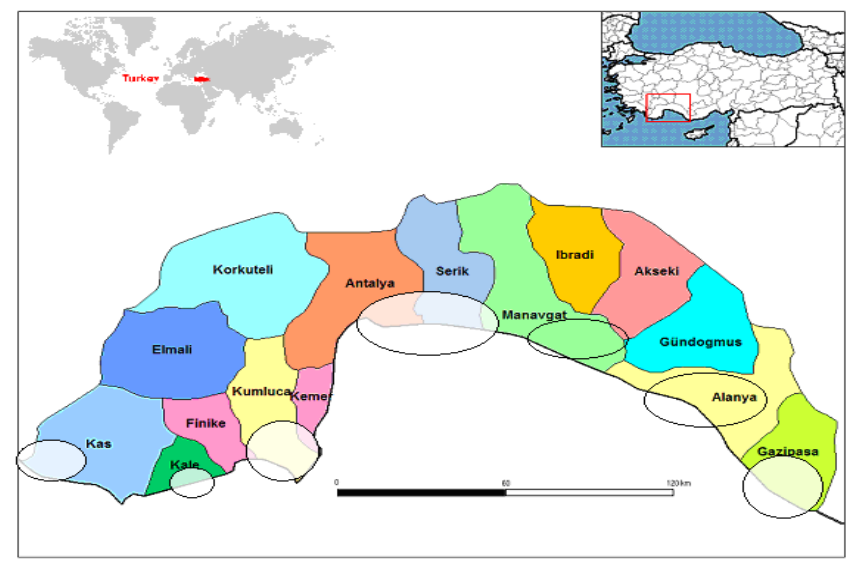

Fig. 1: Map of greenhouse regions in Antalya, Turkey

The geological materials of greenhouse area are mainly of calcareous nature and nearby to Mediterranean sea with average $57,8 \mathrm{~m}$ altitude. The land is influenced by a Mediterranean climate with a high average annual rainfall (1081,5 $\mathrm{mm} /$ year), the annual average temperature being around $18,7{ }^{\circ} \mathrm{C}, 63,8 \%$ average humidity and average 164 sunny days per year. As for greenhouses, the annual temperature is higher inside than outside, and most of them are watered by sprinklers with ground water source at the same point. All greenhouses have passive ventilation to control temperature and humidity inside. A great number of greenhouse soils is artificially built up with a different layer of sand, organic matter and other soil source.

Groundwater Sampling and Analysis: Water samples were collected in polyethylene (HDPE) bottles (washed with detergent then with double-distilled water followed by $2 \mathrm{M}$ nitric acid, then double-distilled water again and finally with sampled water). Water samples were acidified with $10 \%$ $\mathrm{HNO}_{3}$ for metal analysis, samples were stored in an ice-box and brought to the laboratory and kept refrigerated and analysed immediately within $24 \mathrm{~h}$.

Samples were analyzed for nitrate as NO3-N by the Cadmium Reduction Flow InjectionMethod, Standard Method $4500 \mathrm{NO}_{3}-\mathrm{N}$ [6]. Other routine analysis in water samples were analysed according to Standard methods recommended by APHA [7]. $\mathrm{pH}$ was measured by digital $\mathrm{pH}$ meter, electrical conductivity was measured by conductometry. Alkalinity was determined by titration with $0.01 \mathrm{~N}_{2} \mathrm{SO}_{4}$, Total dissolved solids (TDS) was measured by TDS meter. Dissolved oxygen (DO), biological oxygen demand (BOD) was measured by Wrinkler's method and chemical oxygen demand (COD) by Reflux method [7]. pH, electrical conductivity (EC), DO and nitrate were measured on site.

To determine heavy metals in water samples, $10 \mathrm{ml}$ of aqua regia and $1 \mathrm{ml}$ of perchloric acid added to $100 \mathrm{ml}$ of water samples in a culture test tube, then incubated at $80^{\circ} \mathrm{C}$ in a water bath, after total digestion and subsequent cooling, the solution was diluted to $50 \mathrm{ml}$ and analyzed for heavy metals. For the determination of 'total' heavy metal concentrations, water samples were digested in aqua regia $\left(1: 3 \mathrm{HNO}_{3} / \mathrm{HCl}\right)$ and $\mathrm{HCLO}_{4}$ according to the international standard [8] Zn, Cd, $\mathrm{Ni}$ and $\mathrm{Pb}$ concentrations of water and greenhouse soil samples were analysed using ICP-MS under optimised measurement conditions.

Pollution Evaluations: Selected environmental pollution indexes for water samples were used for comprehensive and integrated evaluation of parameters.

HPI index: was developed by assigning a rating or weightage (Wi) for each chosen parameter. In computing the HPI for the present water quality data, the concentration limits i.e. the standard permissible value (Si) and highest desirable value (Ii) for each parameter were taken from the WHO standards.

The HPI is determined by using the expression below [9]:

$$
H P I=\frac{\sum_{i=1}^{n} W i Q i}{\sum_{i=1}^{n} W i}
$$

Where Qi is the sub-index of the ith parameter. Wi is the unit weightage of the ith parameter and $n$ is the number of parameters considered. The sub-index (Qi) is calculated by

$$
Q i=\sum_{i=1}^{n} \frac{\{M i(-) I i\}}{S i-I i} \times 100
$$

Where, $\mathrm{Mi}$, Ii and Si are the monitored value of heavy metal, ideal and standard values of the ith parameter, respectively. The sign (-) indicates numerical differences of the two values, ignoring the algebraic sign.

Heavy Metal Evaluation Index (HEI): HEI, gives an overall quality of the water with respect to heavy metals, and is computed as:

$$
H E I=\sum_{i=1}^{n} \frac{H c}{H m a c}
$$

Where, Hc and Hmac are the monitored value and maximum admissible concentration (mac) of its parameter, respectively [10].

Degree of contamination (Cd): The contamination factor (Cfi) is defined as the ratio of heavy metal concentration in the soil to the background value:

The contamination index (Cd) summarizes the combined effects of several quality parameters considered harmful to household water, and is calculated as follows:

Where 


$$
C f i=\frac{\text { CAI }}{C \text { Ni }}-1
$$

$\mathrm{C} f \mathrm{i}=\left(\mathrm{C}_{A i} / \mathrm{C}_{N i}\right)-1 ; \mathrm{C} f i, \mathrm{C}_{A i}$ and $\mathrm{C}_{N i}$ represent contamination factor, analytical value and upper permissible concentration of the ith component, respectively, and $\mathrm{N}$ denotes the normative value. Here, $\mathrm{C}_{N i}$ is taken as MAC. The contamination levels were classified by their intensities, ranging from 1 to $3\left(\mathrm{C}_{\mathrm{d}}<1\right.$ : low, $1<\mathrm{C}_{\mathrm{d}}<3$ = medium, $3<\mathrm{C}_{\mathrm{d}}=$ high) [10].

Target hazard quotient (THQ): The methodology for estimation of target hazard quotient (THQ) although does not provide a quantitative estimate on the probability of an exposed population experiencing a reverse health effect, but it offers an indication of the risk level due to pollutant exposure. This method was available in US EPA Region III Risk based concentration table and it is described by the following equation [11]:

$$
T H Q=\frac{E_{F Y} \times E_{D} \times F_{l R} \times C_{m} \times 10^{-\mathrm{d}}}{R_{f D} \times B_{w} \times A_{T}}
$$

Where $E_{F r}$ is exposure frequency (365 days/year); $E_{D}$ is the exposure duration (70 years), equivalent to the average lifetime; $F_{I R}$ is the food ingestion rate (2000 g/person/day (FAO, 2005); $\mathrm{Cm}$ is the contaminant concentration in water ( $\mu \mathrm{g} \mathrm{g}_{-} 1$ ); $\mathrm{R}_{\mathrm{fD}}$ is the oral reference dose of contaminant (US EPA, 1997, 2000); Bw is the average body weight (70 kg), and $A_{T}$ is the averaging exposure time for non-carcinogens (365 days/ year $x E_{D}$ ).

Hazard Index (HI): For carcinogenic health effects posed by contaminant in drinking water, the Hazard index (HI) was calculated using the following equation [12]. A HI value more than 1 (HI>1) shows a significant risk level. The higher the value, the greater the likelihood of adverse non-carcinogenic health effect.

$$
\mathrm{HI}=\sum_{n=1}^{\mathrm{i}} T H Q n
$$

Potential ecological risk index (RI) : Potential ecological risk index (RI), which was developed to scree sediment contamination degree caused by heavy metals was introduced to assess the ecological risk degree of heavy metals in present water, soil and sediments [13]. The value of RI can be calculated by the following formulas:

$$
\begin{gathered}
R I=\sum_{i=1}^{n} E_{\gamma}^{i} ; E_{\gamma}^{i}=T_{\gamma}^{i} \times C_{f}^{i} \\
C_{f}^{i}=\frac{c_{D}^{i}}{c_{B}^{i}}
\end{gathered}
$$

where RI is the sum of the potential risk of individual heavy metal, Er i is the potential risk of individual heavy metal, Tr is the toxic-response factor for a given contaminant, Cfi is the contamination factor, $\mathrm{C}_{\mathrm{D}} \mathrm{i}$ is the present concentration of heavy metals, and $C_{B} i$ is the maximum permissible concentration of contaminant.

Statistical analyses were performed by using SPSS-16 for Windows program.

\section{RESUlT AND DISCUSSION}

Land altitude and groundwater table in greenhouse areas: Land Altitude and groundwater table in greenhouse regions of Antalya are given in Figure 2. Land altitude of greenhouse regions are varied in a wide range and groundwater table is changed depending on the regions. Finike, Kaş, Kumluca, Manavgat regions have a low altitude, very near to Mediterranean sea and groundwater table of these regions are below the sea level. This means that there is a possiblity seawater intrusion to aquifers in these regions.

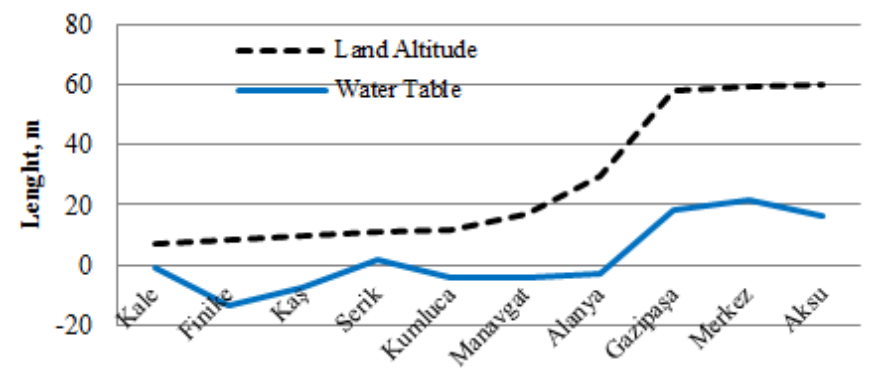

Fig. 2. Altitude and groundwater table of greenhouse regions in the greenhouse regions of Antalya, Turkey

Groundwater Properties: Physico-chemical characteristics of groundwaters in the majority of greenhouse areas were within the acceptable limit values and differences in characteristics among the regions were found statistically important (Table 1). Groundwaters have low electrical conductivity, slightly alkaline reaction, low and moderate alkalinity. Although Finike, Kaş, Kumluca, Manavgat regions have a low altitude and very near to Mediterranean sea, there were not detected a high salinity values in these groundwaters. Dissolved oxygen (DO), biological oxygen demand (BOD), chemical oxygen demand (COD) and total dissolved solids (TDS) were detected in acceptable ranges. These values indicate that groundwaters in greenhouse regions were not polluted by organic solids, and physichemically, may be acceptep clean.

However total $\mathrm{NO}_{3}{ }^{-}$values of groundwaters were generally excessed permissible safe limits [14] for drinking waters. High concentration of $\mathrm{NO}_{3}^{-}$in these areas is of course may be due to highly intensive agricultural practices for all season. Mineralized nitrogen fertilizers applied in greenhouses appeared to be the dominant source of $\mathrm{NO}_{3}{ }^{-}$in the groundwaters, with contributions from native soil organic matter, and organic amendments. Leaching of nitrates into shallow groundwater under greenhouse agriculture may be accepted high because of the relatively large irrigation density and fast chemical and microbial degradation under the greenhouse conditions.

Nitrate pollution evaluation values of groundwaters are indicated in Figure 3. PEI values of groundwaters were below the limit value (40). THQ values in Aksu, Manavgat, Alanya, Gazipaşa and Kaş regions were exceeded limit value 1. Nitrate $\mathrm{C}_{\mathrm{d}}$ values of groundwaters were generally found in low levels. However, $C_{d}$ was found in moderate levels in Manavgat and Alanya regions. These evaluations show that due to higher contents of $\mathrm{NO}_{3}^{-}$there are a possible health risks for the 
consumptions of groundwaters as drinking water in a moderate and long-term in the greenhouse regions.

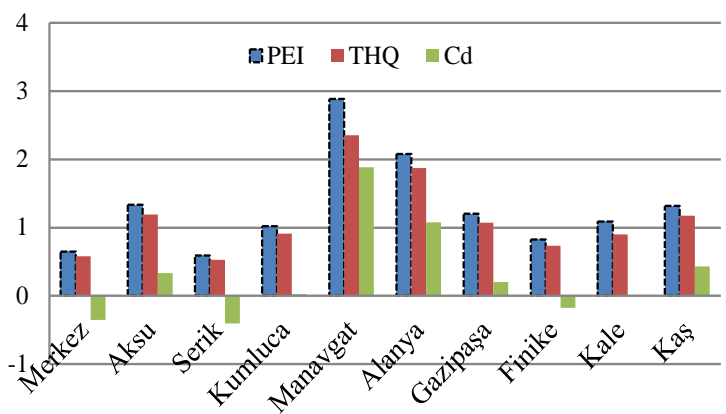

Fig. 3 Some pollution characteristics of $\mathrm{NO}_{3}{ }^{-}$in the groundwaters.

\section{Groundwater Heavy Metal Characteristics}

Total As and Fe contents of all ground waters with the exception of Kale site were above the permissible pollution limits (Table 2). Zinc content of groundwaters in Seri and Kaş sites were exceeded a bit more the permissible limits. Cupper and $\mathrm{Pb}$ were detected above the referenced limits in groundwaters in Kaş and Aksu sites, All other metal concentrations in ground waters of greenhouse areas were below the referenced toxicity limits for drinking waters.

HPI values of groundwaters are shown in Figure 4. All groundwaters except in Aksu site were below the refenced limit value 100. Thus all groundwaters except Aksu regions could be accepted clean level in view of metal concentrations.

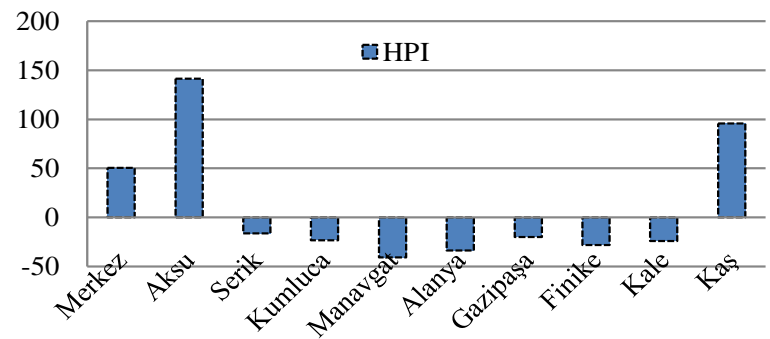

Fig. 4. Heavy metal pollution index (HPI) values of groundwaters in the greenhouse areas.

Heavy metal contamination factor (Cfi) values all metals except Fe were in none to low level (Table 4). Iron Cfi values in groundwaters of Merkez, Aksu, Serik, Alanya and Kaş sites were found between low and moderate levels. Totally, metal contamination degree $\left(C_{d}\right)$ values of groundwaters in the greenhouse sites were below the critical value 1 . According to this parameter all of groundwater samples may be considered as less contaminated.

HEI values for all of metals in groundwaters of all sites of were below the critical value 40 (Table 3 ). Thus, all of groundwater samples may be considered as less contaminated and may be acceptable clean.

Er and RI values of heavy metals in the groundwaters are shown in Table 5. Er values of individual metals in all sites were below the minimum referenced value 40 . RI values that represent the potential ecological risks of all metals in groundwaters of all sites were below the minimum referenced value 150. Er and RI values have not set for Fe element. According to these results, there can not be expected an ecoloogical risk in a short and medium term.

The heavy metal contamination of groundwaters and the potential health risk were evaluated by THQ and HI (Table 6). THQ values of individual heavy metals were all lower than 1 . The cumulative risk of all heavy metals (HI) through the drinking of groundwaters also has not exceeded limit value 1 . This indicated that the daily intake of individual metals through the drinking of groundwaters was unlikely to cause an adverse health risk.

Variation in metal concentrations, HPI, HEI, Er, RI, THQ and $\mathrm{HI}$ values of groundwaters, Cfi values of $\mathrm{Fe}, \mathrm{Zn}, \mathrm{Mn}$ and $\mathrm{Cu}$ of groundwaters, $\mathrm{C}_{\mathrm{d}}$ values among the sites were found statisticaly significant. Land altitude, water table properties, and differences of agricultural practices among the greenhouse regions may be affected on pollution and contamination characteristics of groundwaters.

\section{CONCLUSION}

Land altitude of greenhouse regions are varied in a wide range and groundwater table is changed depending on the regions. Physico-chemical characteristics of groundwaters in the majority of greenhouse areas were within the acceptable limit values and differences in characteristics among the regions were found statistically important. Groundwaters have low electrical conductivity, slightly alkaline reaction, low and moderate alkalinity. DO, BOD, COD and TDS were detected in acceptable ranges. However total $\mathrm{NO}_{3}{ }^{-}$values of groundwaters were generally excessed permissible safe limits for drinking waters.

Nitrate pollution evaluation values of groundwaters are indicated that due to higher contents of $\mathrm{NO}_{3}^{-}$there are a possible health risks for the consumptions of groundwaters as drinking water in a moderate and long-term in the greenhouse regions. Total As and Fe contents of all ground waters with the exception of Kale site were above the permissible pollution limits. All other heavy metal concentrations of groundwaters were below the limits.

HPI values of all groundwaters except in Aksu site were below the refenced limit value 100 . Heavy metal contamination factor (Cfi) values for all metals except Fe were in none to low level. Totally, metal contamination degree $\left(\mathrm{C}_{\mathrm{d}}\right)$ 
TABLE 1

Some Physico-Chemical Parameters Of Groundwaters In The Greenhouse Regions Of Antalya, Turkey.

\begin{tabular}{|c|c|c|c|c|c|c|c|c|c|}
\hline Sites & $\begin{array}{l}\text { Temperature, } \\
{ }^{\circ} \mathrm{C}\end{array}$ & $\begin{array}{c}\text { EC, } \\
\mu \mathrm{S} \mathrm{cm}^{-1}\end{array}$ & $\mathrm{pH}$ & $\begin{array}{l}\text { Alkalinity } \\
\text { mg L-1 }\end{array}$ & $\begin{array}{l}\mathrm{NO}_{3} \text {, } \\
\mathrm{mg} \mathrm{L}^{-1}\end{array}$ & $\begin{array}{c}\text { DO } \\
\text { mg L-1 }\end{array}$ & $\begin{array}{l}\text { BOD } \\
\mathrm{mg} \mathrm{L}^{-1}\end{array}$ & $\begin{array}{l}\text { COD } \\
\mathrm{mg} \mathrm{L}^{-1}\end{array}$ & $\begin{array}{l}\text { TDS } \\
\mathrm{mg} \mathrm{L}^{-1}\end{array}$ \\
\hline 1. Centre & 18,0 & 624,4 & 7,36 & 120 & 32,6 & 5,54 & 5,25 & 5,85 & 775 \\
\hline 2. Aksu & 18,4 & 680,7 & 7,34 & 180 & 66,6 & 5,57 & 6,35 & 6,45 & 815 \\
\hline 4. Kumluca & 19,4 & 823,5 & 7,49 & 205 & 51,1 & 5,45 & 8,65 & 9,05 & 675 \\
\hline 5. Manavgat & 18,0 & 300,7 & 8,07 & 330 & 144,2 & 5,70 & 2,28 & 3,35 & 215 \\
\hline 8. Finike & 17,8 & 1307,4 & 7,51 & 190 & 41,3 & 5,33 & 5,30 & 5,60 & 1050 \\
\hline 9. Kale & 19,0 & 916,8 & 7,05 & 80 & 50,4 & 5,26 & 9,25 & 9,55 & 890 \\
\hline 10. Kaș & 18,2 & 776,1 & 7,25 & 95 & 71,70 & 5,34 & 8,25 & 8,35 & 990 \\
\hline Significancy & $5,203^{* *}$ & $2,784^{* *}$ & $3,243^{* *}$ & $6,225^{* *}$ & $5,02 * *$ & $9,131^{* *}$ & $4,771^{* *}$ & $5,654^{* *}$ & $14,254 * *$ \\
\hline Limit values [14] & 25 & $<750$ & $6,5-8,5$ & 600 & 50 & $5<$ & $<10$ & $<10$ & $<1500$ \\
\hline
\end{tabular}

TABLE 2

HEAVY METAL CONCENTRATIONS OF GROUNDWATERS IN THE GREENHOUSE REGIONS OF ANTALYA, TURKEY.

\begin{tabular}{|c|c|c|c|c|c|c|c|c|c|}
\hline Sites & $\begin{array}{l}\text { Fe, } \\
\mu \mathrm{g} \mathrm{L}^{-1}\end{array}$ & $\begin{array}{l}\mathrm{Zn}, \\
\mu \mathrm{g} \mathrm{L}^{-1}\end{array}$ & $\begin{array}{l}\text { Mn, } \\
\mu \mathrm{g} \mathrm{L}^{-1}\end{array}$ & $\begin{array}{l}\mathrm{Cu}, \\
\mu \mathrm{g} \mathrm{L}^{-1}\end{array}$ & $\begin{array}{l}\text { Cd, } \\
\mu \mathrm{g} \mathrm{L}^{-1}\end{array}$ & $\begin{array}{c}\mathrm{Pb} \\
\mu \mathrm{g} \mathrm{L}^{-1}\end{array}$ & $\begin{array}{c}\mathrm{Ni}, \\
\mu \mathrm{g} \mathrm{L}^{-1}\end{array}$ & $\begin{array}{c}\text { Cr, } \\
\mu \mathrm{L} \mathrm{L}^{-1}\end{array}$ & $\begin{array}{l}\text { As, } \\
\mu \mathrm{g} \mathrm{L}^{-1}\end{array}$ \\
\hline 1. Merkez & 1089 & 112 & 16,49 & 9,59 & 0,284 & 6,35 & 5,57 & 14,94 & 13,17 \\
\hline 3. Serik & 773 & 212 & 9,47 & 4,50 & 0,041 & 3,07 & 4,85 & 20,91 & 16,58 \\
\hline 4. Kumluca & 546 & 80 & 42,76 & 7,79 & 0,082 & 4,35 & 5,49 & 4,65 & 17,20 \\
\hline 5. Manavgat & 403 & 174 & 11,12 & 17,08 & 0,065 & 1,65 & 3,58 & 4,00 & 19,31 \\
\hline 7. Gazipaşa & 541 & 97 & 6,27 & 4,88 & 0,150 & 8,04 & 3,24 & 9,66 & 19,87 \\
\hline 8. Finike & 379 & 103 & 12,61 & 11,11 & 0,434 & 7,09 & 3,05 & 6,71 & 17,94 \\
\hline 9. Kale & 242 & 102 & 24,49 & 5,05 & 0,174 & 6,22 & 4,95 & 13,65 & 17,06 \\
\hline 10. Kaş & 748 & 214 & 17,71 & 63,43 & 0,151 & 4,47 & 9,58 & 16,94 & 17,48 \\
\hline Significancy & $5,483 * *$ & $9,021 * *$ & $2,825^{* *}$ & $3,464 \mathrm{~ns}$ & $1,667 \mathrm{~ns}$ & $1,081 \mathrm{~ns}$ & $2,644 * *$ & $1,03 \mathrm{~ns}$ & $2,123^{*}$ \\
\hline
\end{tabular}

*: $\mathrm{P}<0,05,{ }^{* *}: \mathrm{P}<0,01$, ns: no significancy

TABLE 3

Heavy Metal Evaluation Index Values (Hei)Of Groundwaters In The Greenhouse Regions Of Antalya, Turkey.

\begin{tabular}{|c|c|c|c|c|c|c|c|c|c|c|}
\hline Sites & $\begin{array}{l}\text { Sample } \\
\text { number }\end{array}$ & $\mathrm{HEI} \mathrm{Fe}$ & HEI Zn & HEI Mn & $\mathrm{HEI} \mathrm{Cu}$ & $\mathrm{HEI} \mathrm{Cd}$ & $\mathrm{HEI} \mathrm{Pb}$ & $\mathrm{HEI} \mathrm{Ni}$ & $\mathrm{HEI} \mathrm{Cr}$ & HEI As \\
\hline 1. Merkez & 29 & 3,629 & 0,560 & 0,165 & 0,480 & 0,095 & 0,635 & 0,279 & 0,747 & 0,659 \\
\hline 3. Serik & 13 & 2,578 & 1,061 & 0,095 & 0,225 & 0,014 & 0,307 & 0,243 & 1,045 & 0,829 \\
\hline 4. Kumluca & 28 & 1,820 & 0,401 & 0,428 & 0,390 & 0,027 & 0,435 & 0,275 & 0,233 & 0,860 \\
\hline 5. Manavgat & 4 & 1,344 & 0,871 & 0,111 & 0,854 & 0,022 & 0,165 & 0,180 & 0,200 & 0,966 \\
\hline 7. Gazipaşa & 12 & 1,804 & 0,485 & 0,063 & 0,244 & 0,050 & 0,804 & 0,163 & 0,483 & 0,994 \\
\hline 8. Finike & 7 & 1,264 & 0,515 & 0,126 & 0,556 & 0,145 & 0,709 & 0,153 & 0,336 & 0,897 \\
\hline 9. Kale & 12 & 0,808 & 0,508 & 0,245 & 0,252 & 0,058 & 0,622 & 0,248 & 0,682 & 0,853 \\
\hline 10. Kaş & 10 & 2,493 & 1,072 & 0,177 & 3,171 & 0,050 & 0,447 & 0,479 & 0,847 & 0,874 \\
\hline Significancy & & 5,483 ** & 9,022 ** & 2,825 * & 3,464 ** & $1,666 \mathrm{~ns}$ & $1,081 \mathrm{~ns}$ & $2,644 \mathrm{~ns}$ & $1,030 \mathrm{~ns}$ & $2,123 \mathrm{~ns}$ \\
\hline
\end{tabular}

*: $P<0,05,{ }^{* *}: \mathrm{P}<0,01$, ns: no significancy; 
TABLE 4. HEAVY METAL CONTAMINATION FACTOR (CFI) AND METAL CONTAMINATION DEGREE (C ${ }_{D}$ ) VALUES OF GROUNDWATERS IN THE GREENHOUSE REGIONS OF ANTALYA, TURKEY.

\begin{tabular}{|c|c|c|c|c|c|c|c|c|c|c|c|}
\hline Sites & $\begin{array}{l}\text { Sample } \\
\text { number }\end{array}$ & Cfi Fe & Cfi Zn & Cfi Mn & Cfi Cu & Cfi Cd & $\mathrm{Cfi} \mathrm{Pb}$ & Cfi Ni & $\mathrm{Cfi} \mathrm{Cr}$ & Cfi As & $C_{d}$ \\
\hline 1. Merkez & 29 & 2,629 & $-0,440$ & $-0,835$ & $-0,520$ & $-0,905$ & $-0,365$ & $-0,722$ & $-0,253$ & $-0,342$ & $-0,195$ \\
\hline 3. Serik & 13 & 1,578 & 0,060 & $-0,905$ & $-0,775$ & $-0,986$ & $-0,693$ & $-0,758$ & 0,045 & $-0,171$ & $-0,289$ \\
\hline 4. Kumluca & 28 & 0,820 & $-0,599$ & $-0,572$ & $-0,610$ & $-0,973$ & $-0,565$ & $-0,726$ & $-0,767$ & $-0,140$ & $-0,459$ \\
\hline 5. Manavgat & 4 & 0,344 & $-0,130$ & $-0,889$ & $-0,146$ & $-0,978$ & $-0,835$ & $-0,821$ & $-0,800$ & $-0,034$ & $-0,477$ \\
\hline 7. Gazipaşa & 12 & 0,804 & $-0,515$ & $-0,937$ & $-0,756$ & $-0,950$ & $-0,196$ & $-0,838$ & $-0,517$ & $-0,007$ & $-0,435$ \\
\hline 8. Finike & 7 & 0,264 & $-0,485$ & $-0,874$ & $-0,444$ & $-0,855$ & $-0,291$ & $-0,848$ & $-0,664$ & $-0,103$ & $-0,478$ \\
\hline 9. Kale & 12 & $-0,192$ & $-0,492$ & $-0,755$ & $-0,747$ & $-0,942$ & $-0,378$ & $-0,753$ & $-0,317$ & $-0,147$ & $-0,525$ \\
\hline 10. Kaş & 10 & 1,493 & 0,072 & $-0,823$ & 2,172 & $-0,950$ & $-0,553$ & $-0,521$ & $-0,153$ & $-0,126$ & 0,068 \\
\hline Significancy & & 5,483 ** & 9,019 ** & 2,825 * & 3,464 ** & $1,666 \mathrm{~ns}$ & $1,081 \mathrm{~ns}$ & $2,645 \mathrm{~ns}$ & $1,030 \mathrm{~ns}$ & $2,123 \mathrm{~ns}$ & 3,488 ** \\
\hline
\end{tabular}

*: $\mathrm{P}<0,05$, **: $\mathrm{P}<0,01$, ns: no significancy;

TABLE 5. ECOLOGICAL RISK (ER) AND POTENTIAL ECOLOGICAL RISKS (RI) VALUES OF HEAVY METALS IN THE GROUNDWATERS OF GREENHOUSE REGIONS OF ANTALYA, TURKEY.

\begin{tabular}{|c|c|c|c|c|c|c|c|c|c|}
\hline Sites & $\begin{array}{l}\text { Sample } \\
\text { number }\end{array}$ & $\mathrm{Er} Z \mathrm{n}$ & $\mathrm{ErCu}$ & $\mathrm{ErCd}$ & $\mathrm{Er} \mathrm{Pb}$ & $\mathrm{Er} \mathrm{Ni}$ & $\mathrm{Er} \mathrm{Cr}$ & ErAs & $\mathrm{RI}$ \\
\hline 1. Merkez & 29 & 0,56 & 2,40 & 2,84 & 3,18 & 1,39 & 1,49 & 6,58 & 18,44 \\
\hline 3. Serik & 13 & 1,06 & 1,13 & 0,41 & 1,54 & 1,21 & 2,09 & 8,29 & 15,72 \\
\hline 4. Kumluca & 28 & 0,40 & 1,95 & 0,82 & 2,18 & 1,37 & 0,47 & 8,60 & 15,78 \\
\hline 5. Manavgat & 4 & 0,87 & 4,27 & 0,65 & 0,82 & 0,90 & 0,40 & 9,66 & 17,57 \\
\hline 7. Gazipaşa & 12 & 0,48 & 1,22 & 1,50 & 4,02 & 0,81 & 0,97 & 9,94 & 18,94 \\
\hline 8. Finike & 7 & 0,51 & 2,78 & 4,34 & 3,54 & 0,76 & 0,67 & 8,97 & 21,58 \\
\hline 9. Kale & 12 & 0,51 & 1,26 & 1,74 & 3,11 & 1,24 & 1,37 & 8,53 & 17,75 \\
\hline 10. Kaş & 10 & 1,07 & 15,86 & 1,51 & 2,23 & 2,39 & 1,69 & 8,74 & 33,50 \\
\hline Mean & & $0,55^{\star}$ & $2,65^{\star \star}$ & $1,53^{*}$ & $3,77^{\star \star}$ & $1,29 *$ & $1,19^{*}$ & $8,30 * *$ & $19,28^{* *}$ \\
\hline
\end{tabular}

*: $\mathrm{P}<0,05,{ }^{\star *}: \mathrm{P}<0,01$, ns: no significancy;

TABLE 6. THQ AND HI VALUES OF HEAVY METALS IN THE GROUNDWATERS OF GREENHOUSE REGIONS OF ANTALYA, TURKEY.

\begin{tabular}{|c|c|c|c|c|c|c|c|c|c|c|}
\hline Sites & Sample & $\mathrm{Fe}$ & $\mathrm{Zn}$ & $\mathrm{Cu}$ & $\mathrm{Cd}$ & $\mathrm{Pb}$ & $\mathrm{Ni}$ & $\mathrm{Cr}$ & As & HI \\
\hline 1. Merkez & 29 & 0,0030 & 0,011 & 0,007 & 0,008 & 0,045 & 0,008 & 0,0001 & 0,008 & 0,090 \\
\hline 2. Aksu & 24 & 0,0022 & 0,006 & 0,003 & 0,003 & 0,141 & 0,007 & 0,0001 & 0,009 & 0,171 \\
\hline 4. Kumluca & 28 & 0,0017 & 0,008 & 0,005 & 0,005 & 0,044 & 0,007 & 0,0001 & 0,010 & 0,066 \\
\hline 5. Manavgat & 4 & 0,0025 & 0,017 & 0,012 & 0,002 & 0,012 & 0,005 & 0,0001 & 0,011 & 0,062 \\
\hline 6. Alanya & 9 & 0,0025 & 0,004 & 0,001 & 0,003 & 0,031 & 0,005 & 0,0001 & 0,011 & 0,058 \\
\hline 8. Finike & 7 & 0,0012 & 0,010 & 0,008 & 0,012 & 0,051 & 0,004 & 0,0001 & 0,010 & 0,097 \\
\hline 9. Kale & 12 & 0,0008 & 0,010 & 0,004 & 0,005 & 0,044 & 0,007 & 0,0001 & 0,010 & 0,080 \\
\hline 10. Kaş & 10 & 0,0030 & 0,021 & 0,045 & 0,011 & 0,068 & 0,011 & 0,0001 & 0,009 & 0,168 \\
\hline Mean & 0,0030* & $0,010 * *$ & $0,005^{*}$ & $0,006^{*}$ & & & & $0,0001 \mathrm{~ns}$ & $0,008 \mathrm{~ns}$ & $0,076^{*}$ \\
\hline
\end{tabular}

values of groundwaters in the greenhouse sites were below the critical value 1 . Er and RI values of metals in all sites were below the minimum referenced values. THQ and HI values of heavy metals were all lower than harmful level. According to evaluation parameters, generally, it can be concluded that all ground waters in regional size may be considered less contaminated, and in point of heavy metals and pollutants is in acceptable limits. High nitrate contents of groundwaters due to agricultural activities all season seem the main threats for public health.

The environmental characteristics and the historic trends in yield and agrochemical inputs in the study sites suggest that the results may be typical of many greenhouse growing areas 
in Mediterrranean areas where greenhouse cultivation has intensified since the beginning of 1970s.

\section{ACKNOWLEDGMENT}

This research was sponsored by TUBITAK (The Scientific and Technological Council of Turkey). Author would like to thank to TUBITAK for the financial support of the project (TOVAG-111O711).

\section{REFERENCES}

[1] Suthar, S., P. Bishnoi, S. Singh, P.K. Mutiyar, A.K. Nema et al. 'Nitrate contamination in groundwater of some rural areas of Rajasthan,India', J. Hazard. Mater., 2009, 171: 189-199. http://dx.doi.org/10.1016/j.jhazmat.2009.05.111

[2] Cruz, J.V., Silva, M.O., Diaz, M.I., Prudencio, M.I. 'Groundwater composition and pollution due to agricultural practices at sete cidades volcano (Azores, Portugal)', Applied Geochemistry, 2013, 29:162-173. http://dx.doi.org/10.1016/j.apgeochem.2012.11.009

[3] Heaton, T., Stuart, M., Sapiano, M., Sultana, M. 'An isotope study of the sources of nitrate in Malta's groundwater', J. Hydrology, 2012, 414(415):244-254. http://dx.doi.org/10.1016/j.jhydrol.2011.10.037

[4] Mahvi, A.H., J. Nouri, A.A. Babei, R. Nabizadeh. 'Agricultural activities impact on groundwater nitrate pollution'. Int. J. Environ. Sci. Tech., 2005, 2: 41-47. http://dx.doi.org/10.1007/BF03325856

[5] Khan, I., H. Ullah, M. Imran. 'Nitrate and phosphate pollution in surface and ground water in Western Malaysia', J. Chem. Soc. Pak., 2007, 29: 315-320.

[6] Clesceri, L., Greenberg, A.E., Eaton, A.D. 'Standard Methods for the Examination of Water and Wastewater, 20th edition', American Public Health Association, 1998, Washington, DC.

[7] APHA, 'Standard Methods for the Examination by Water Waste Water', 16th Edn. APHA, 1985, Washington.

[8] ISO 11466 International Standard. 'Soil quality-extraction of trace elements soluble in aqua regia', 1995,03-01.

[9] Mohan, S.V., Nithila, P., Reddy, S.J. 'Estimation of heavy metal in drinking water and development of heavy metal pollution index. J. Environmental Sci. Health', 1996, 283-289.

[10] Edet, A.E., Offiong, O.E. 'Evaluation of water quality pollution indices for heavy metal contamination monitoring. A study case from Akpabuyo-Odukpani area, Lower Cross River Basin (southeastern Nigeria)', Geojournal, 2002, 57, 295-304. http://dx.doi.org/10.1023/B:GEJO.0000007250.92458.de

[11] United States, Environmental Pollution Agency (USEPA), 'Integrated risk information system', 2007, Available from: (http://cfpub.epa.gov/ncea/iris/index.cfm?fuseaction=iris.showSubstanc eList).

[12] Xu, X., Zhao, Y., Zhao, X., Wang, Z., Deng, W. 'Sources of heavy metal pollution in agricultural soils of a rapidly industrializing area in the Yangtze delta of China', Ecotoxicology and Environmental Safety, 2014, 108, 161-167. http://dx.doi.org/10.1016/j.ecoenv.2014.07.001

[13] Hakanson, L. 'An ecological risk index for aquatic pollution control: A sedimentological approach', Water Research, 1980, 14: 975-1001. http://dx.doi.org/10.1016/0043-1354(80)90143-8

[14] WHO 'Guidelines for Drinking-Water Quality', Vol. 1, 2000recommendations, 3rd ed. Geneva: World Health Organization, 2006. 